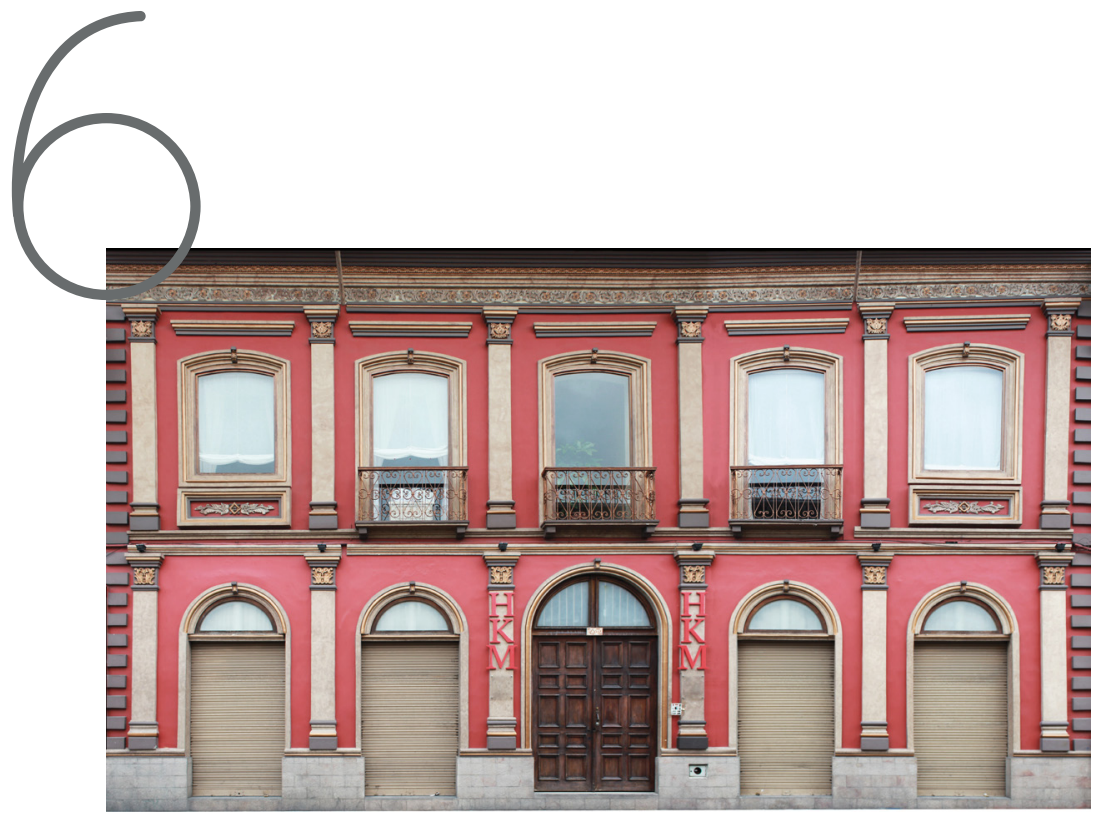

\title{
INFLUENCIAS DE ESTILOS ARQUITECTÓNICOS EN EL CENTRO HISTORICO DE CUENCA
}

\author{
Roura Burbano, Alexandra
} alexandraroura@gmail.com

Ochoa Arias, Paúl pochoa@uazuay.edu.ec 


\section{Resumen}

En el presente artículo se describe la influencia que ha recibido la arquitectura cuencana desde los diferentes estilos foráneos como: el Neoclásico Francés, el Art Nouveau, el Art Déco, el Racionalismo y otros, los mismos que se evidencian con notoriedad en algunas de las edificaciones del centro histórico de la ciudad.

Palabras Clave: Centro histórico Cuenca, arquitectura, patrimonio edificado, Neoclásico Francés, Art Nouveau, Art Déco.

\section{INFLUENCES ON ARCHITECTURAL STYLES IN THE HISTORIC CENTER OF CUENCA}

\section{Abstract}

The present article describes the influence that Cuenca's architecture has received from different foreign styles such as: French neoclassical, Art Nouveau, Art Deco, Rationalism, and others, which are strongly evident in some of the buildings in the Historic Center of the city.

Keywords: Historic Centre of Cuenca, architecture, building heritage, French neoclassical, Art Nouveau, Art Deco. 


\section{Introducción}

La arquitectura está asociada a los acontecimientos sociales y culturales de cada época y lugar. Latinoamérica $\mathrm{y}$, por tanto, nuestro país y ciudad han sido influenciados directamente por Europa y Norteamérica, lo que ha dejado huellas en la cultura de nuestros pueblos, y por consecuencia en nuestra arquitectura.

A finales del siglo XIX y principios del XX, el excedente económico conseguido por la burguesía cuencana a partir de la exportación de cascarilla y del sombrero de paja toquilla, cuyos réditos constituyeron un gran porcentaje del total nacional de importaciones, y la producción minera de oro de lavadero en la región austral, pusieron a Cuenca en el panorama nacional e internacional y le permitieron abandonar su vida silenciosa, casi rural, que arrastraba de la época colonial para abrir las puertas a la modernización $y$ al progreso de la vida urbana.

La floreciente economía trajo consigo la apertura cultural de la ciudad, principalmente por los viajes realizados al exterior por los nuevos ricos de Cuenca. Esto permitió a la ciudad tener contacto con el mundo exterior, lo que provocó la evolución de una ciudad maravillada con el progreso mundial.

Cuenca tuvo una transformación intensa, mayor que en el resto de su historia. Así en 1913 la ciudad inauguró su primera entidad crediticia: el Banco del Azuay. En 1917 arribó a la ciudad el primer automóvil, en 1919, se fundó 
la cámara de comercio y también se inauguró la primera planta eléctrica. Para 1926, Cuenca contaba con una importante red telefónica, y llegó la novedad del cine mudo.

En 1928 abrió las puertas la sucursal del Banco Central del Ecuador en Cuenca. En 1930 se inauguró el sistema de agua potable, en 1935 comenzó el adoquinamiento de sus calles; y en 1939 se realizaron los primeros vuelos comerciales. En resumen Cuenca abrió sus puertas al progreso y a la modernización, por un estrecho vínculo comercial y cultural con las potencias capitalistas.

Como consecuencia lógica del excedente económico y la influencia cultural extranjera, la elite cuencana siempre estuvo a la cabeza de las transformaciones arquitectónicas de la urbe.

\section{La Influencia externa}

La nueva arquitectura que se manifestaba en la ciudad era patrocinada por la burguesía cuencana en un afán de seguir la moda que se vivía en las grandes capitales del mundo. Primero maquillaron sus casas con pilastras, frontones y frisos decorados y ocultaron la cubierta inclinada de teja, tradicional de la arquitectura popular, por medio de finos balaustres y coronas decoradas. Sintiéndose así la influencia del Neoclásico Francés cuya presencia se observó en la ciudad a finales del siglo XIX y principios del $X X$. Después con los vientos de modernidad que traía el nuevo siglo las fachadas adoptaron la línea sinuosa del Art Nouveau, en especial en los detalles de herrería; y una vez entrada la década de los 20 las edificaciones cuencanas 
van dejando atrás las líneas onduladas para geometrizar su decoración.

Para la década de los 50 y con el auge de la arquitectura internacional, el hormigón armado de Auguste Perret, los preceptos racionales de Le Corbusier y Mies van der Rohe, etc., Cuenca abre sus puertas a una arquitectura más limpia cuyos principales elementos son las líneas rectas y los volúmenes puros.

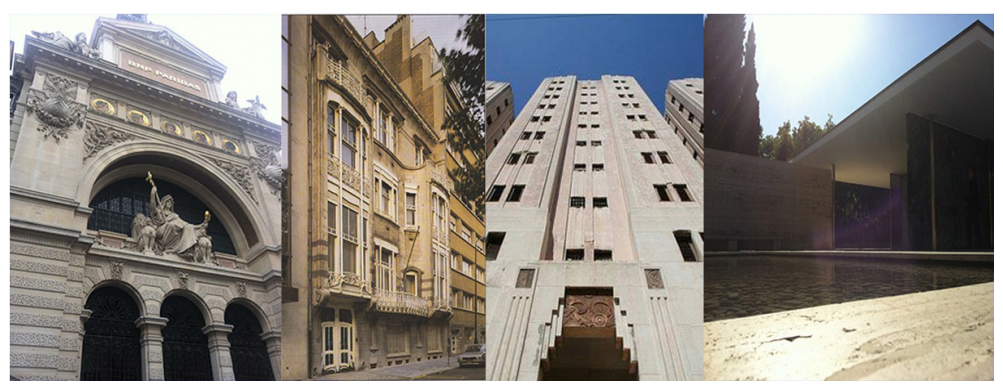

Figura 1. Arquitectura extranjera (Fuente Hardy, William)

Cada estilo arquitectónico presenta elementos característicos que pueden ser identificados y reconocidos dentro de las fachadas del centro histórico, tomando en cuenta siempre que se trata de una influencia, y que el grado de interpretación de nuestros artistas constructores y artesanos genera fachadas únicas en la arquitectura cuencana. 


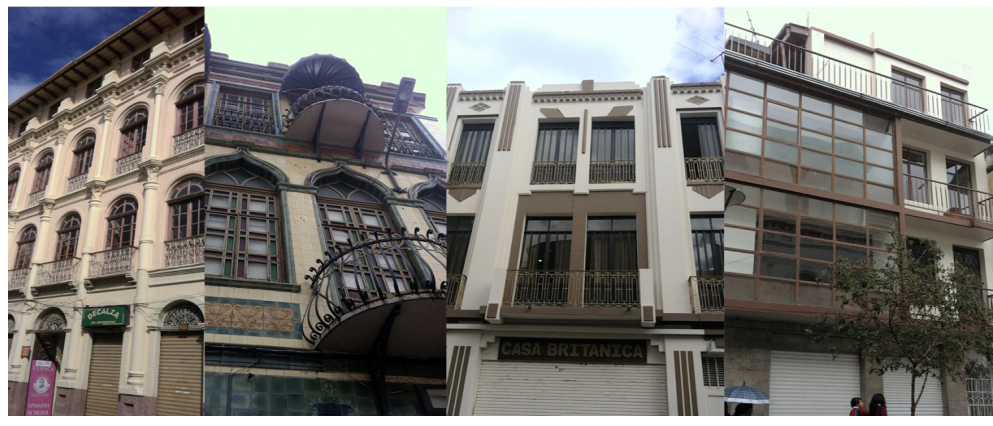

Figura 2. Arquitectura cuencana (Fuente Alexandra Roura).

\section{Influencia del Neoclásico Francés}

El Neoclásico presente en la ciudad proviene especialmente de la influencia de la cultura francesa en nuestro medio a principio del siglo $\mathrm{XX}$, algunos de los elementos característicos de este estilo son:

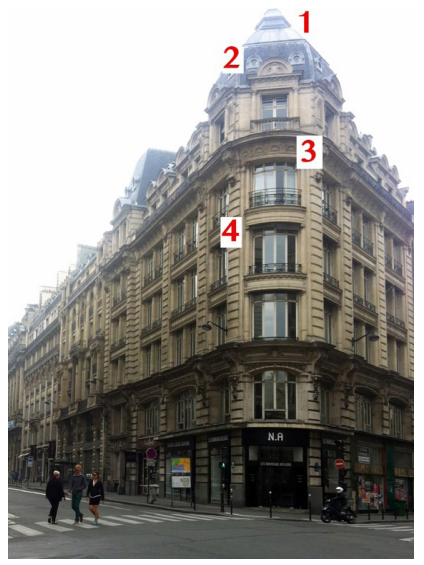

1. Diferenciación de esquinas por medio de cúpulas y frontones.

2. Ventana circular u ovalada en el techo.

3. Marcapisos con molduras decorativas.

4. Almohadillado.

Figura 3. Arquitectura francesa (Fuente Alexandra Roura). 


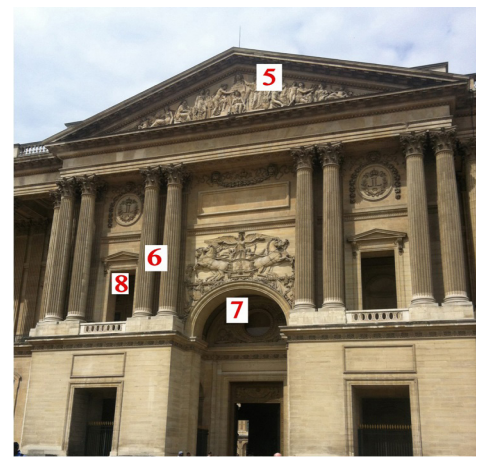

5. Coronas de remate y frontones triangulares esculpidos.

6. Columnas y pilastras con capiteles clásicos que abracan uno o más pisos.

7. Utilización de arcos de medio munto para enmarcar vanos de puertas y ventanas.

8. Enmarcación de vanos con molduras fileteadas.

Figura 4. Arquitectura francesa (Fuente Alexandra Roura).

En el centro histórico de Cuenca se encuentran edificaciones de obra nueva, concebida en su totalidad bajo este estilo, así: el colegio Benigno Malo, la Corte Superior de Justicia, el Banco del Azuay, etc.

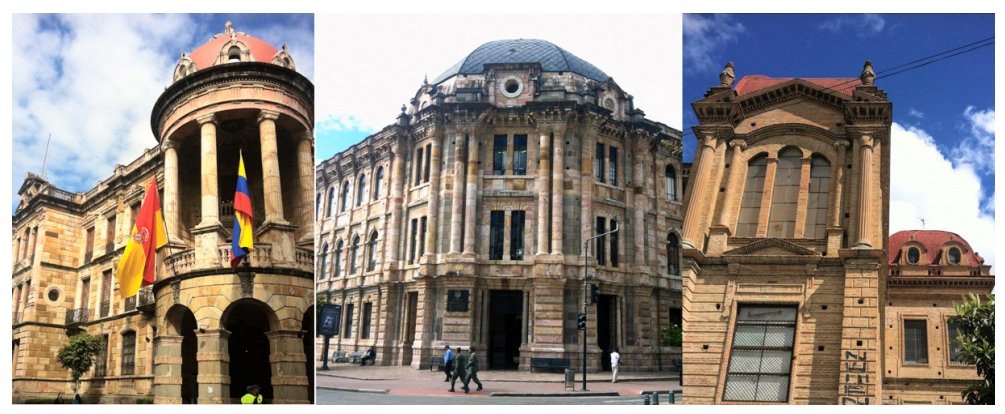

Figura 5. Arquitectura francesa en Cuenca (Fuente Alexandra Roura). 
También se observa edificaciones cuya fachada fue reemplazada para dejar el lenguaje tradicional y adoptar el estilo Neoclásico, pero la distribución interna permanece intacta.

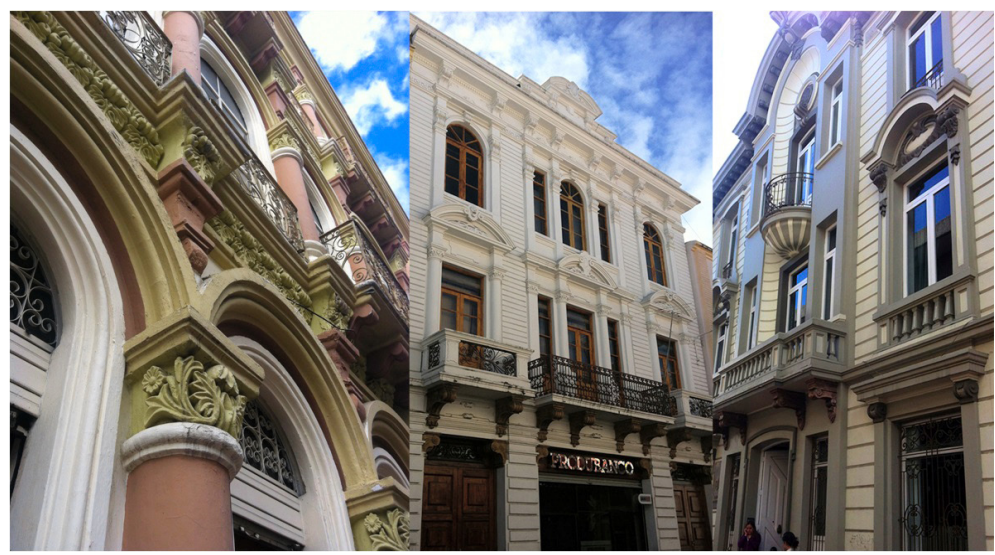

Figura 6. Arquitectura Neoclásica en Cuenca (Fuente Alexandra Roura).

Los elementos neoclásicos se utilizaron también para modernizar las fachadas de las edificaciones tradicionales, solamente como elementos decorativos superpuestos, que venían a maquillar la fachada existente.

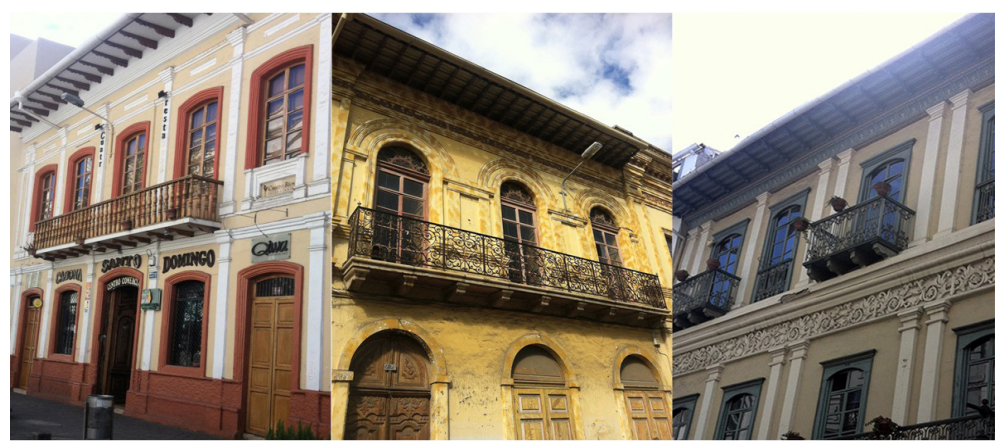

Figura 7. Arquitectura Neoclásica en Cuenca (Fuente Alexandra Roura). 
Los elementos son tomados del Neoclásico, interpretados y adaptados a las fachadas de las edificaciones cuencanas.

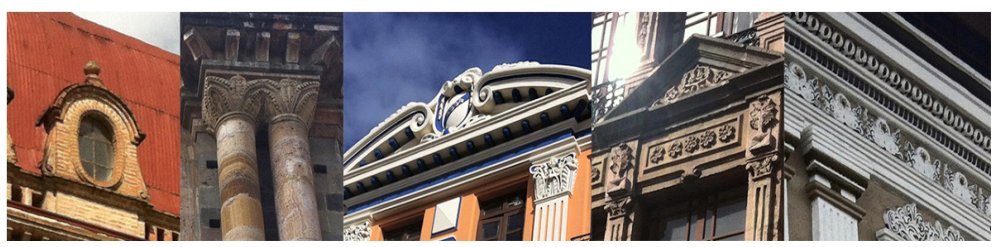

Figura 8. Arquitectura Neoclásica en Cuenca (Fuente Alexandra Roura).

\section{El Art Nouveau y Art Déco}

Los estilos Art Nouveau y Art Déco fueron estilos con una diversidad infinita en donde los artistas pusieron su huella original e inventiva muy personal, resultando casi imposible la generalización de sus términos compositivos; mas existió en cada uno de ellos elementos que los ubicaron en un estilo u otro.

El estilo Art Nouveau es un estilo novedoso, que llegó a romper los parámetros rígidos del Neoclásico y se regó en todos los aspectos de la vida cotidiana, especialmente en el arte gráfico; pero también alcanzó a muebles, joyas y arquitectura. Sus características esenciales son: 


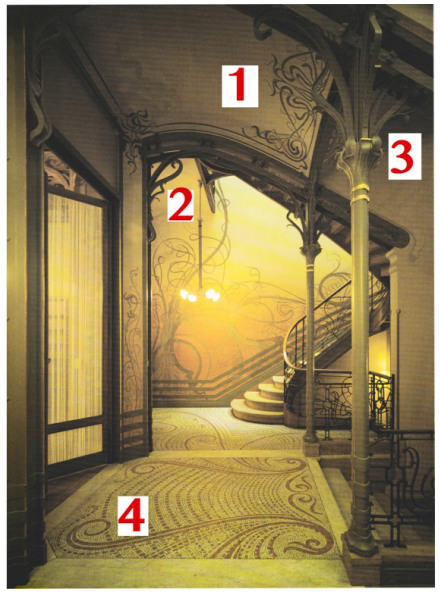

1. Un carácter esencialmente lineal.

2. Continuidad de las formas.

3. La naturaleza como influencia directa.

4. Utiliza una línea curva y sinuosa, que denota ligereza y movimiento.

Figura 9. Estilo Art Nouveau (Fuente Hardy, William).

El estilo Art Déco llega como oposición a la línea sinuosa del Art Nouveau para convertirla en rectas y curvas rígidas con sentido geométrico, inspiradas en culturas exóticas. Sus principales características son:

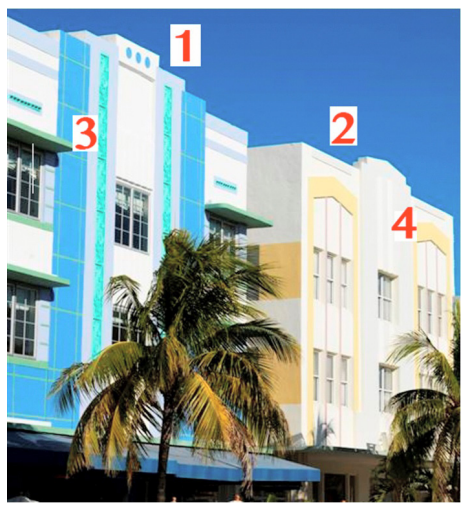

1. Escalamiento y oblicuidad.

2. Utilización continua de la simetría.

3. Utiliza la naturaleza como inspiración compositiva.

4. Carácter esencialmente geométrico.

Figura 10. Estilo Art Déco (Fuente autor, "Los Estilos Art Nouveau y Art Déco en Cuenca (1920-1940)"). 
Tanto el estilo Art Nouveau como el estilo Art Déco, por su carácter sustancialmente decorativo, se los encuentra en las fachadas de las casas del centro histórico de Cuenca a modo de decoración de las fachadas, que pueden ser de edificaciones nuevas o edificaciones preexistentes, que cambiaron su fachada para ir a la par con las tendencias de moda.

La arquitectura del Art Nouveau como tal no existe en la ciudad, pero sus rasgos característicos se observan en los detalles decorativos de algunas edificaciones, cuyos balcones, ventanas, puertas o frisos se encuentran decorados con la representativa línea ondulada del estilo.

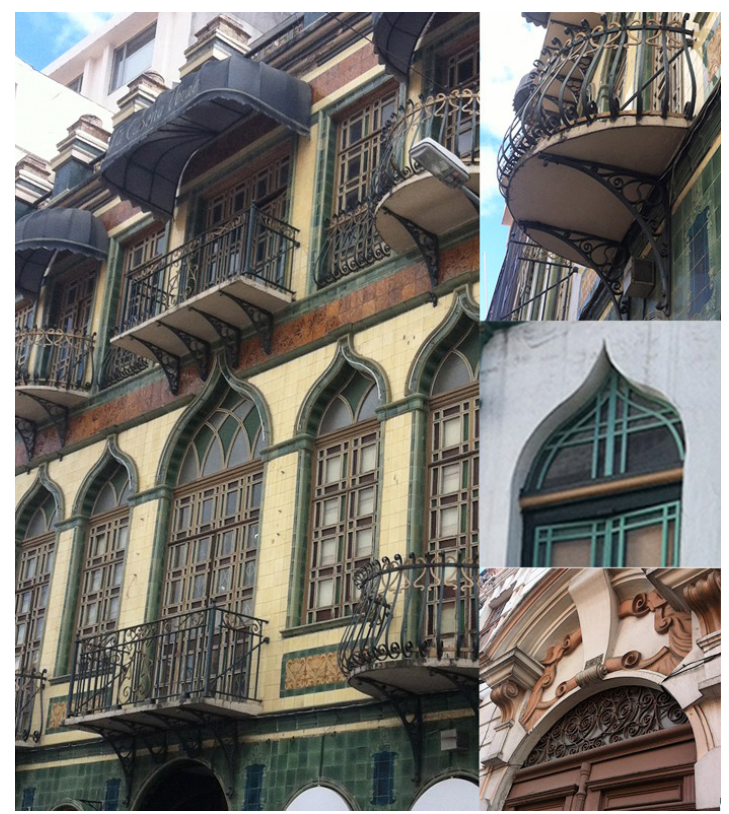

Figura 11. Estilo Art Nouveau en Cuenca (Fuente Alexandra Roura). 
El estilo Art Déco en su momento se tomó las fachadas de las casas en un afán modernizante, pero la distribución interna de las edificaciones nuevas se mantuvo intacta.

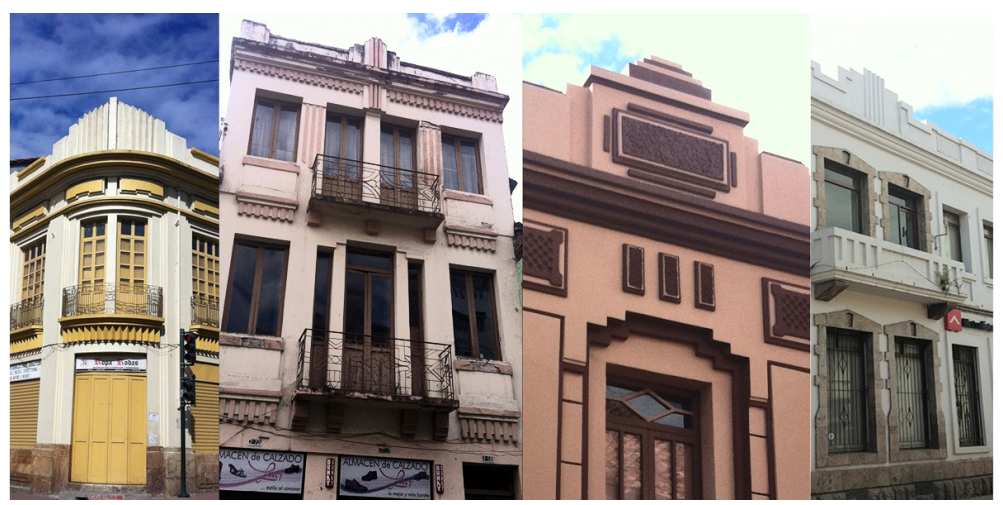

Figura 12. Estilo Art Déco en Cuenca (Fuente Alexandra Roura).

Algunas fachadas de edificaciones preexistentes fueron sustituidas en unos casos, con estilo Art Déco y en otras se utilizaron elementos decorativos superpuestos a manera de maquillaje.

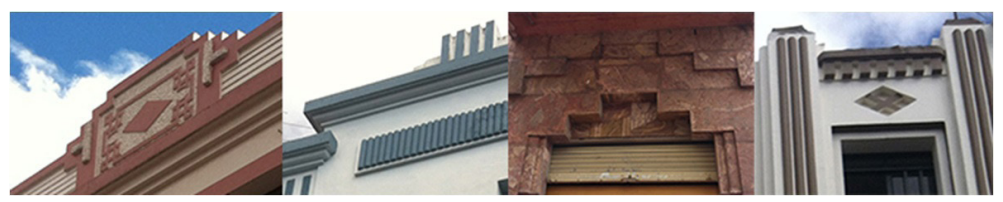

Figura 13. Estilo Art Déco en Cuenca (Fuente Alexandra Roura). 


\section{Lo ecléctico}

En el centro histórico de Cuenca encontramos también otro tipo de edificaciones, cuyas fachadas presentan elementos de diferentes momentos arquitectónicos, es decir, una fachada ecléctica, sin estilo definido.

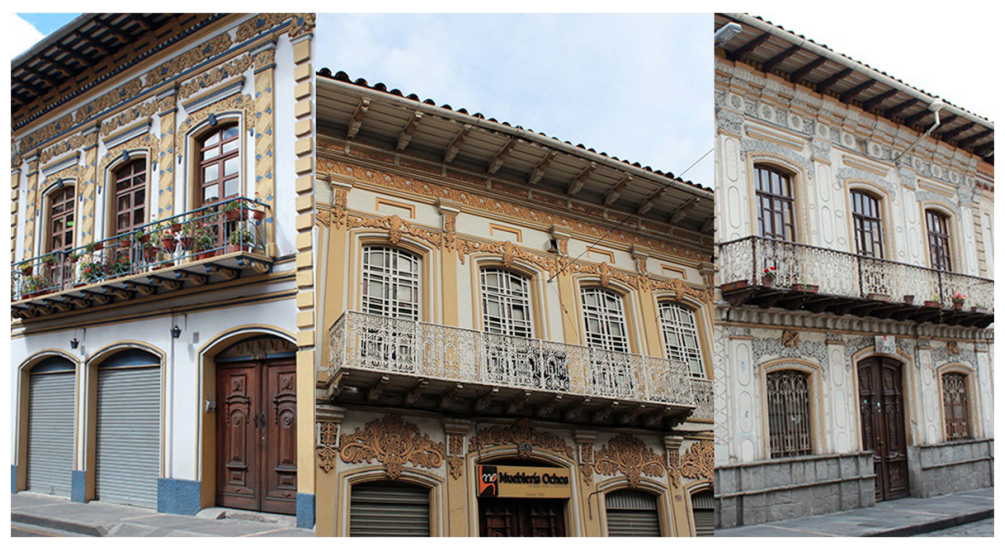

Figura 14. Fachadas eclécticas en Cuenca (Fuente Alexandra Roura).

\section{La arquitectura racionalista y la tradicional}

En la segunda mitad del siglo XX, la arquitectura internacional con las técnicas nuevas de construcción, las teorías de los grandes arquitectos y las ideas urbanas de la nueva ciudad aparece en Cuenca, coincidiendo con la expansión de la ciudad fuera de los límites del casco antiguo, tejiendo su influencia en su mayoría en la ciudad moderna fuera del centro histórico.

Aparece la arquitectura racionalista de línea recta y simple, de edificaciones unifamiliares aisladas, donde las decoraciones se dejan de lado para dejar ver los 
materiales por sí mismos; y posteriormente el regreso a la arquitectura vernácula con elementos tradicionales como los aleros y las cubiertas inclinadas de teja.

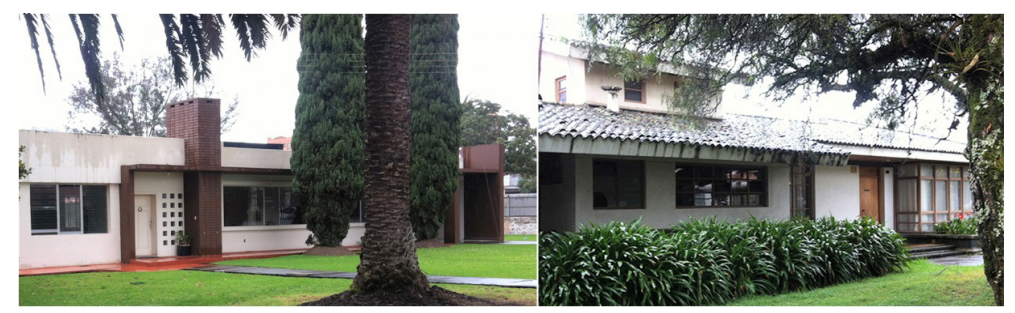

Figura 15. Arquitectura racionalista (izquierda) y vernácula (derecha) en Cuenca (Fuente Alexandra Roura).

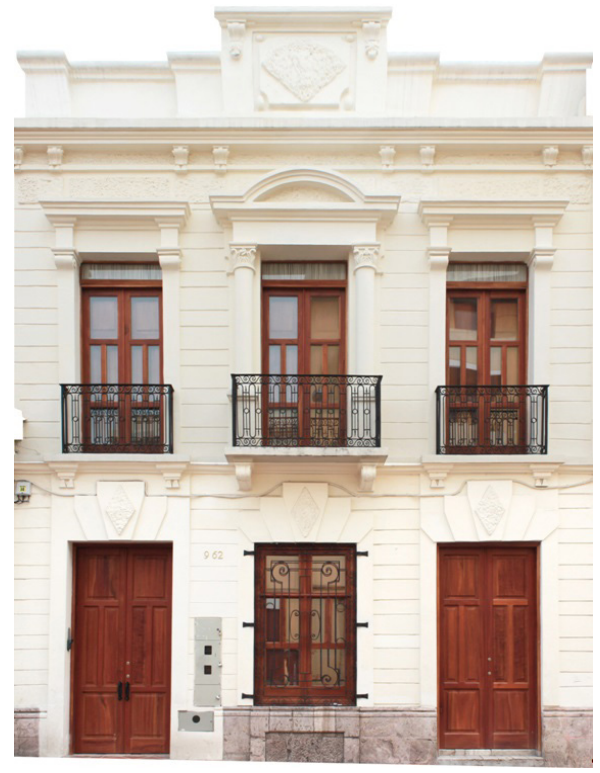

Figura 16. Arquitectura Neoclásica en Cuenca, Juan Jaramillo 9-62 (Fuente Ochoa, Paúl, et al. (2013). "El Patrimonio Edificado de Cuenca"). 


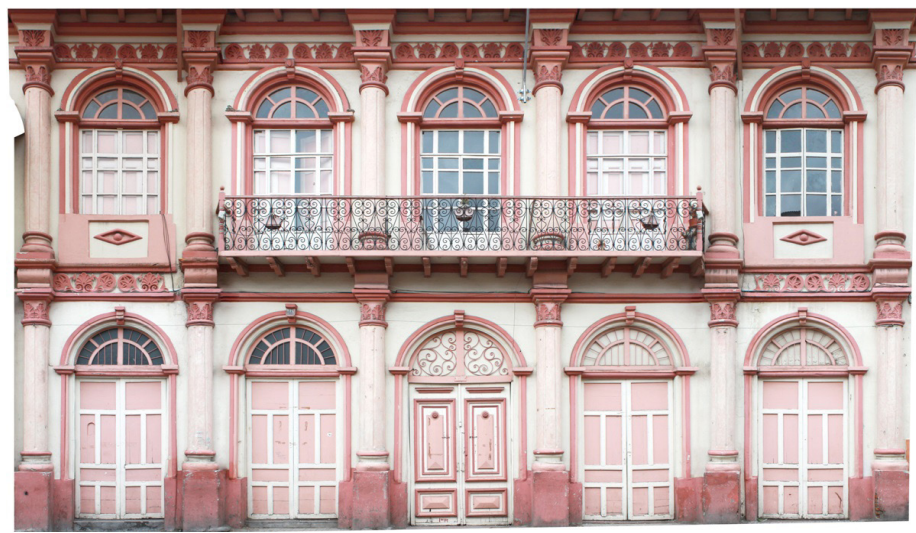

Figura 17. Arquitectura Neoclásica en Cuenca, Juan Jaramillo 9-62 (Fuente Ochoa, Paúl, et al. (2013). "El Patrimonio Edificado de Cuenca").

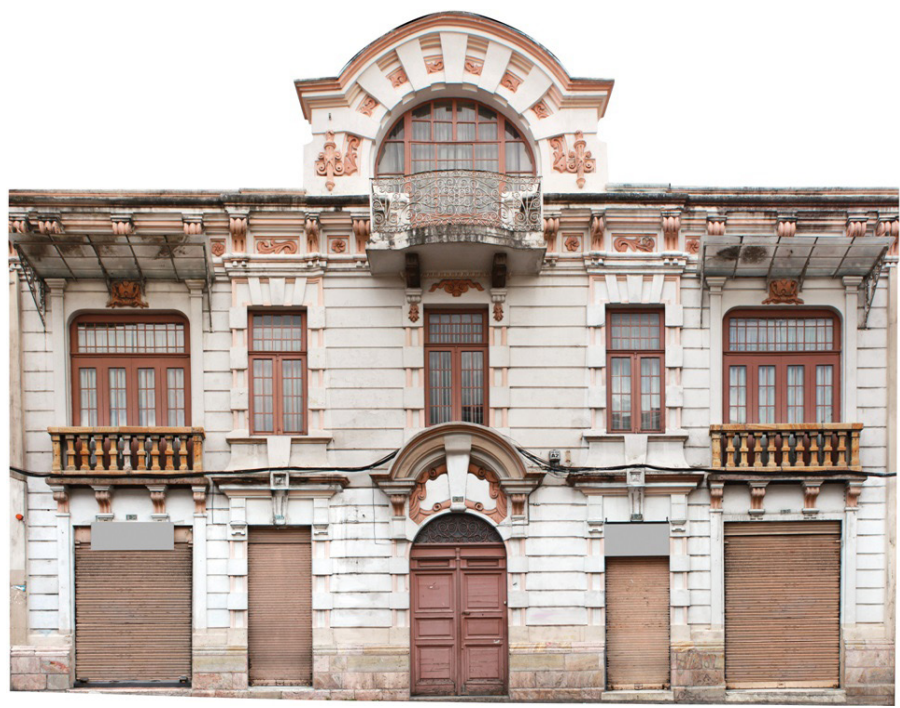

Figura 18. Arquitectura Art Nouveau en Cuenca, Lamar 8-28 (Fuente Ochoa, Paúl, et al. (2013). "El Patrimonio Edificado de Cuenca"). 


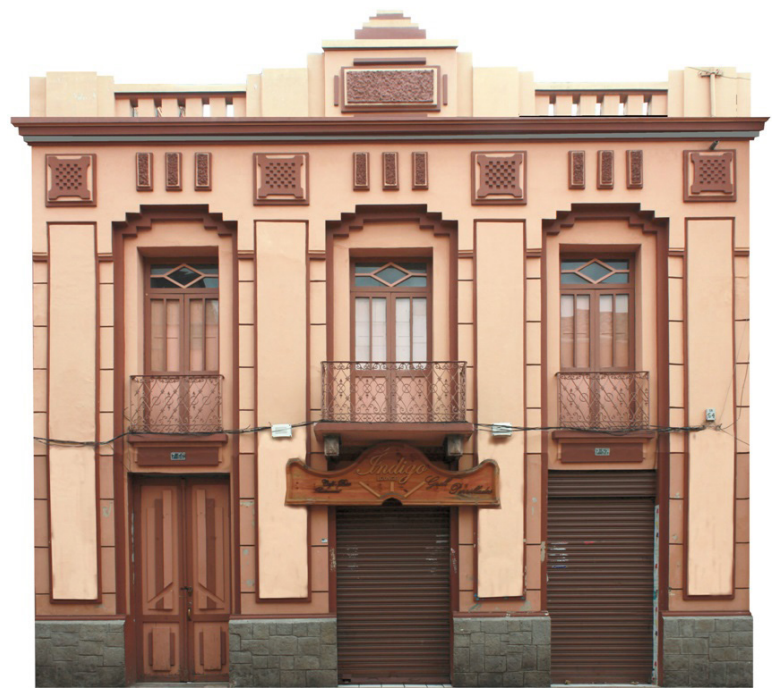

Figura 19. Arquitectura Art Déco en Cuenca, Borrero 7-60 (Fuente Ochoa, Paúl, et al. (2013). "El Patrimonio Edificado de Cuenca").

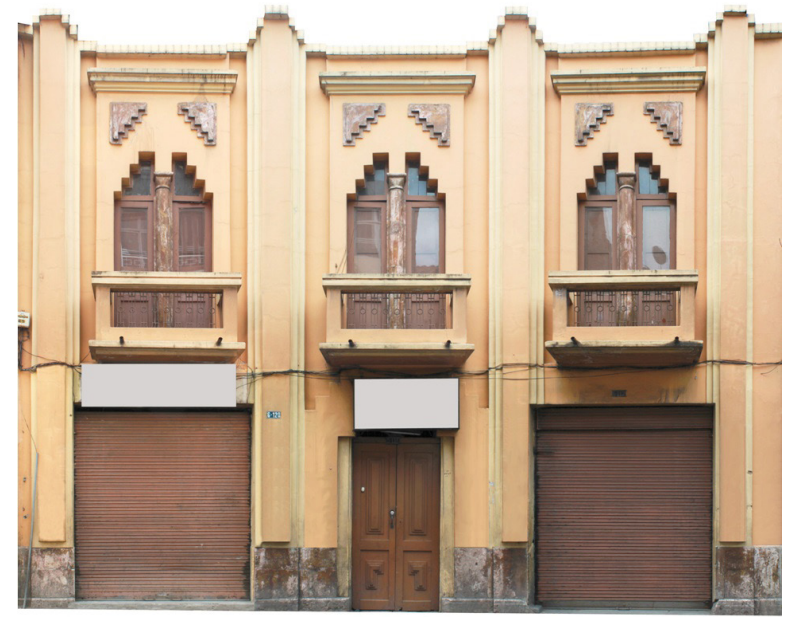

Figura 20. Arquitectura Art Déco en Cuenca, Borrero 7-60 (Fuente Ochoa, Paúl, et al. (2013). "El Patrimonio Edificado de Cuenca"). 


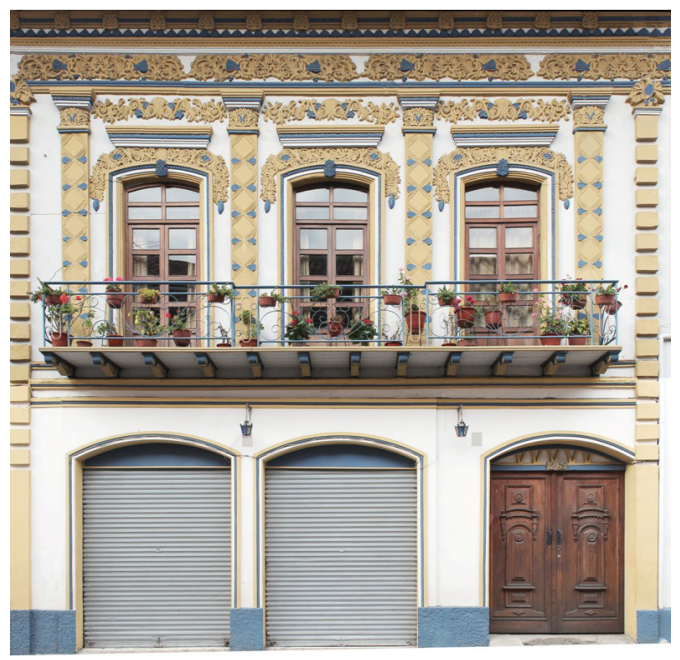

Figura 21. Arquitectura ecléctica en Cuenca, Bolívar 12-69 (Fuente Ochoa, Paúl, et al. (2013). "El Patrimonio Edificado de Cuenca")

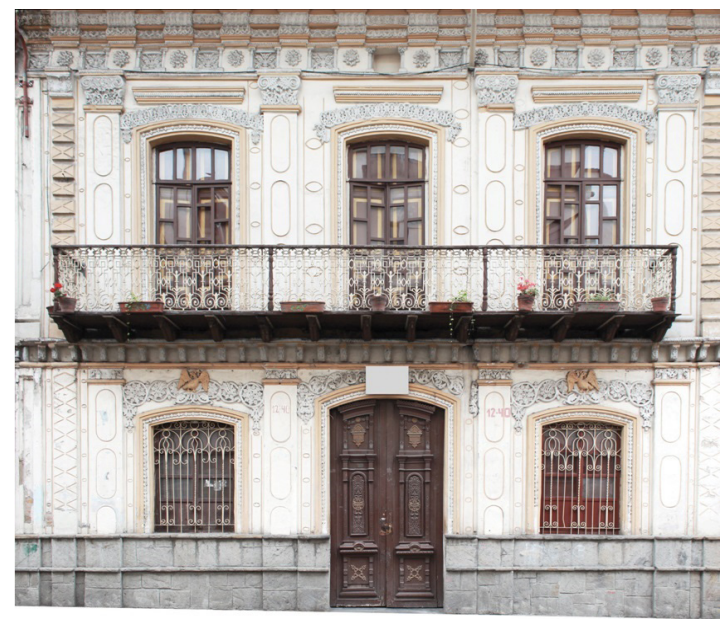

Figura 22. Arquitectura ecléctica en Cuenca, Bolívar 12-69 (Fuente Ochoa, Paúl, et al. (2013). "El Patrimonio Edificado de Cuenca"). 


\section{Conclusiones}

Las características singulares de la ciudad de Cuenca son claramente visibles por medio de sus edificaciones, en efecto, la naturaleza propia de sus habitantes ha hecho de su entorno físico el reflejo de los anhelos y sentimientos que, a lo largo del tiempo, se han materializado en construcciones que conjugan: estética, armonía, función, y le otorgan un carácter especial a la ciudad.

El valor arquitectónico de estas edificaciones, junto con el espacio geográfico y sus habitantes, permitieron que la UNESCO reconociera su centro histórico como Patrimonio Cultural de la Humanidad.

Favorecer la conservación, valoración, recuperación y promoción de este patrimonio es una tarea continua de las diferentes instituciones nacionales, locales y, sobre todo, de sus habitantes.

Con el correr del tiempo, la importancia y la trascendencia que tiene el patrimonio edificado hace que se lo aprecie no solamente como un tema que requiere de un tratamiento de tipo técnico y de conservación, sino y sobre todo, como el asidero de la identidad y pertenencia de una sociedad a un determinado espacio físico.

La identificación de la influencia arquitectónica que caracteriza a las edificaciones, es un elemento que ayuda a entender y valorar la riqueza arquitectónica de la ciudad. Es por ello recomendable continuar desarrollando proyectos como "El Patrimonio Edificado de Cuenca". 


\section{Bibliografía}

- Espinosa, Pedro. Calle, María Isabel (2002). "El Afrancesamiento de Cuenca en la Época Republicana (1860-1940)". Tesis de Graduación, Director: Arq. Carlos Jaramillo Medina. Facultad de Arquitectura y Urbanismo de la Universidad de Cuenca. Cuenca, Ecuador.

- Hardy, William. "Guía del estilo Art Nouveau". Editorial Agata. Madrid. 1997

- Maenz, P. (1989). “Art Déco: 1920-1940”. Editorial Gustavo Gili. Barcelona.

- Ochoa, Paúl, et al. (2013). "El Patrimonio Edificado de Cuenca". Fotogrametría Arquitectural. Registro gráfico Nro. 1. Universidad del Azuay. 2013.

- Ochoa, Paúl (2013). "Fotogrametría Arquitectural: una Herramienta para la Gestión del Patrimonio Edificado". Universidad Verdad No. 60. Universidad del Azuay. Cuenca, Ecuador.

- Roura, Alexandra (2005). "Los Estilos Art Nouveau y Art Déco en Cuenca (1920-1940)". Tesis de Graduación, Director: Arq. Carlos Jaramillo Medina. Facultad de Arquitectura y Urbanismo de la Universidad de Cuenca. Cuenca, Ecuador. 
